\title{
A Conversation Analysis of Repair Strategies in Communication Breakdowns: A Case Study of Algerian Bilingual Students
}

\section{Souad Belgrimet}

Department of English Language and Literature, University of Jordan, Jordan.

\begin{abstract}
The present study seeks to delve into the intricacies of repair strategies used by Algerian bilinguals. The topic of repair strategies has attracted ample attention in the last couple of decades. Consequently, this study is hoped to enrich previous findings. In this respect, the different types of repair strategies used by Algerian bilingual students are explored. Similarly, it attempts to examine the different functions lying at the very heart of each repair strategy. The participants taking part in this study are Algerian bilingual students at the University of Jordan. Data are elicited by audio-recording the participants who, in pairs, were asked to engage in casual conversations. The analysis of the results obtained is couched within the framework of conversation analysis. In addition, the study is a replication of Al Harahshah's (2015) investigation. In fact, the findings indicate that Algerian bilinguals adopt nine different strategies of repair; namely: Expansion, repetition, meta-repair, hesitation, abort and abandon, code switching, abort and restart, avoidance and questioning. In a similar vein, these appear to serve different functions depending on the objective of the speaker and the type of communication breakdown taking place. The conclusions drawn from this paper may constitute basis for a fruitful line of inquiry in forthcoming research.
\end{abstract}

Keywords-Repair strategies, communication breakdowns, conversation analysis, Algerian bilinguals.

\section{INTRODUCTION}

In research spanning over the last decade, the repair strategies deployed to fill the gaps emerging from communication breakdowns have been a matter of great interest for the general public under the assumption that effective communication is a key element of successful everyday interaction between individuals. Indeed, communication is a fundamental means for achieving one's goals on a daily basis. As a result, people need to interact with each other to exchange information and make acquaintances. However, such communication is sometimes interrupted due to diverse factors such as: errors in turn taking and turn allocation, misunderstanding, false starts, problems in hearing, and simultaneous talk to mention but a few.

In fact, in an attempt to define communication, Keyton (2011) holds that communication refers to the process of transporting and conveying information. It similarly refers to the shared understanding taking place between individuals when embarking in an interactional event. Lunenburg (2010) further claimed that, in essence, communication encompasses four fundamental elements, namely: the sender, the receiver, the medium and finally feedback. Indeed, in a communicative act, the sender is the person who encodes information; that is, who initiates communication in order to convey a previously determined idea. This is realized by means of different resources including: words, symbols and a set of gestures. The receiver on the other hand is the addressee whose role is to decode information into meaningful units. The medium is the tool through which the message is transferred. This may be a written article or a phone call. Finally, feedback refers to the reaction of the receiver to the message he/she receives from the sender.

However, it is worth pointing out that even with the presence of these elements, some problems may arise during communication. These appear to be due to a set of barriers. In this respect, Eisenberg (2010) pinpoints to the existence of three main elements of barriers: physical, semantic and psychosocial barriers. First, physical barriers refer to the physical obstacles and limits that might hinder effective communication such as distance between individuals. Second, as its name implies, semantic barriers touch upon the lexical choices made by the sender and the 
way these are used when conveying meaning. Indeed, it is recurrent to come across a word which has different meanings for different people. Finally, the psychosocial barrier encompasses three intricately intertwined components; namely: field of experience, filtering and psychological distance. Field of experience is personspecific as it involves the set of beliefs, values and background of individuals. Accordingly, the addresser and the addressee can encode and decode information only in the context of their fields of experience. It is noteworthy though that if the sender's field of experience overlaps with that of the receiver, communication may become problematic. Filtration is the effect that one's own beliefs and concerns exercise on his/ her understanding and consequently guide it. Finally, psychological distance (Antos, 2011) is in essence similar to physical distance.

The aim of the present study is to capture insights about the set of repair strategies adopted by Algerian bilingual students in everyday life with a focus on self-initiated repair strategies. Similarly, the study tries to cast light on the main functions behind the use of such strategies.

\section{RESEARCH QUESTIONS}

In order to frame and guide the present study, the following research questions are devised:

a) What repair strategies are used by Algerian bilingual students when facing communication breakdowns?

b) What are the different functions that these repair strategies fulfill with regard to communication?

\section{LITERATURE REVIEW}

Given the effects of communication breakdowns in impeding and hindering effective and successful interaction, a multitude of research has been conducted with an eye towards the range of compensatory techniques and repair strategies that might be undertaken to bridge the gap between interlocutors. As a result a number of taxonomies may be encountered in the literature.

\subsection{Types of repair strategies:}

Casting light on self-initiated repair strategies, Schegloff (1979) argued that self-initiated repairs might be either pre or post-positioned. Pre-positioned self-repair strategies takes place when the ongoing utterance includes pauses and instances of inarticulacy and it is repaired within the same turn. Post positioned self-initiated repair on the other hand ensue when the speaker suspects that he/she made a mistake but come to repair it not within the same utterance but in the next.
Similarly, Tarone (1977) attempted to group the different communicative repair strategies into basic categories. His attempt resulted in the emergence of four typologies: Avoidance strategies including topic avoidance and message abandonment; paraphrasing which comprises three sub strategies: approximation, word coinage and circumlocution; appeal for assistance and mime which involves either a complete replacement of verbal output by some gestures or the accompaniment of the verbal output with gestures.

In recent years, emerging awareness seems to take place regarding the interrelationship between conversation analysis and the study of bilingual interaction that was once neglected. In fact, most analyses that took place within this framework had been conducted on monolingual individuals or balanced bilingual children. However, neglect regarding the exploration of adult unbalanced bilinguals' interaction may be noticed.

\subsection{Previous studies on repair strategies:}

Upon trying to investigate the use of repair strategies, Comeau, Genesee and Mendelson (2010) compared bilingual and monolingual children's repairs of some types of breakdowns in conversations experienced by both populations. These occurred when they use a language distinct from that of their interlocutor or for some other reasons like inaudible and ambiguous utterances. To this end, the researcher asked frequently for clarification to trigger children's repairs. The results indicated that there were not significant differences between the set of repairs used by monolingual and bilingual children. Similarly, the research outcomes strengthen the body of evidence that bilingualism does not interfere with the language development of simultaneous bilinguals.

In an attempt to fill the gap between the study of conversation and repair in relation to bilinguals, Gafaranga (2012) tried to investigate where in the repair sequence can language alternation occur and what does language alternation do in repair sequences. It was concluded that there is no constraint as to when language alternation should take place within a repair sequence. Furthermore, language alternation was seen as a repair technique used to overcome conversation breakdowns.

Similarly, Rabab'ah (2013) shed light on the use of repetition and self-initiated repair strategies by EFL students in Germany and Jordan (non-English speaking countries) when facing communication breakdowns in story retelling. To this end, third year students enrolled in the linguistics department at Chemnitz Technical University in Germany and the University of Jordan. Two short stories were selected from 100 free English short 
stories for EFL learners to trigger the students' use of repair strategies. Students' retelling of the stories was faithfully and carefully transcribed. Subsequently, the researcher detected repair strategies in the transcripts of the spoken discourse of the German and Jordanian learners of English and then classified them into two categories. The mean scores for each category were computed and a t-test was conducted to see whether there was a significant difference between the two groups. The results obtained indicated that both German and Jordanian students made use of repair strategies to compensate their linguistic lacks and to gain more time for retrieving the required items. In a similar vein, it was concluded that repetition was the most widely used repair strategy in contrast with self-initiated repair strategies. However, it is worth mentioning that Jordanian students exhibited more frequent use of repair strategies than German students. This was attributed to their production of many story events. Similarly, the influence of their mother tongue was considered as one factor triggering this result.

In a similar vein, Al Harahshah (2015) shed light on the set of self-initiated repair strategies used in Jordanian spoken Arabic. Accordingly, his investigation was conducted by employing the framework of conversation analysis which is based on a systematic analysis of talk in interaction. In this respect, he selected 36 Jordanian students at Yarmouk university who were divided into pairs and asked to choose any topic they want to talk about in order to obtain casual conversations. The yielded data revealed that Jordanians made use of 10 types of selfinitiated repair strategies. These strategies were approximately in line with Spark's (1994) classification that emerged from his study of the American society. Accordingly, their conducts resulted in the following categories: expansion, hesitation, repetition, replacement, insertion, abort and restart, abort and abandon, deletion, meta-repair and modify order.

\subsection{Theoretical framework:}

The framework adopted in this investigation is Conversation Analysis. In fact, Wooffitt (2005) argues that Conversation Analysis (CA) highlights the ways in which individuals organize their talk during interaction. It investigates rules and practices from an interactional perspective and studies them by means of a close analysis of recordings of real-life interactions

This framework appears to have started in American sociology. Indeed, the sociologists Erving Goffman and Harold Garfinkel prepared the ground in which CA arose. Enabled by the spread of recording techniques that opened a fruitful path for the inspection of interaction, Harvey
Sacks and Emanuel Schegloff established a contemporary paradigm for researching the organization of human action in and through talk in interaction (Sacks, Schegloff and Jefferson, 1974). A principle that may be evinced along these lines is CA reliance on the analysis of turn-taking. Indeed, the accuracy and acceptance of a given utterance depends on the next utterance (ibid).

By the same token, CA assesses the legitimacy and validity of its results by means of a procedure best known as "nextturn proof procedure" (Heritage, 1984). At the core of this procedure is the assumption that, within a conversation, the next utterance is regarded as evidence and confirmation of the clarification of the previous utterance. By way of illustration, a speaker repairs his previous utterance based on the reaction of the listener in the next utterance.

Based on the aforementioned studies, the study at hand seeks to throw light on the set of repair strategies adopted by Algerian bilinguals speaking Algerian Arabic and French. However, it should be borne in mind that Algerian bilinguals appear to include two categories: passive bilinguals who only understand the second language but do not speak or write it and active bilinguals, who speak, write and understand the language. Consequently, when communication takes place between these two types of bilinguals, communicative breakdowns may occur.

\section{RESEARCH METHOD}

\subsection{Participants:}

The participants taking part in the present study are 20Algerian students: four males and sixteen females enrolled in linguistics, literature and mathematics departments at the University of Jordan. Their age ranges from 23 to 25. The students selected are Arabic (Algerian Arabic)-French bilinguals. The participants speak different dialects of Algerian Arabic as they come from different Algerian regions. At the level of detail considered here, it is worth pointing out that while some students are equally proficient in both languages, others are considered as passive bilinguals. That is, they do understand the second language (French) but do not produce utterances using this language.

\subsection{Method of data collection:}

In an attempt to answer the abovementioned research questions, a replication of Al Harahsha's (2015) study was conducted. In fact, the researcher first asked for the participants' approval to take part in the present study and to be recorded. The period of data collection lasted for one week. Once their approval was taken, the participants were asked to work in pairs. Accordingly, they were seated in 
front of each other and asked to select a topic and engage in a conversation. The length of each conversation was ten (10) minutes. In order not to influence the mainstream of the conversation, the researcher activates the audio record and left the participants before they start conversing. It is worth mentioning at this level of detail that some participants did record their conversations at home and send them to the researcher because of their lack of time. The aim behind the freedom regarding the choice of topics lies in the researcher's desire to get casual conversations under the assumption that these are more representative of real life interaction. It is noteworthy though that the conversations took place based on the participants' availability. In order to get valid and reliable results, participants were not informed about the research topic so that their conversations will not be biased and misled.

\subsection{Method of data analysis:}

The participants' productions were recorded and passages encompassing instances of repair strategies were then faithfully transcribed. When analyzing the transcribed conversations, light was shed on the occurrence of communicative breakdowns and most importantly on the set of repair strategies deployed by the students to overcome these breakdowns. To get more reliable, decent and faithful results, the recording of each conversation was heard twice by the researcher to make sure that none of the repair strategies in the conversations was omitted or added by mistake. Students' pauses were mentioned in the transcript. Indeed, every 3 dots represent a pause of one second that was measured with a stop watch. Markee (2000) proposes that transcriptions should encompass the pauses to "provide an exhaustive account of the data potentially available for analysis" (p. 105). To answer the first research question, descriptive statistics was used. That is, the researcher prepared a list of the self-initiated repair strategies previously stated in the Al Harahshah's study (2015) that were matched with Spark's (1994) classification and whenever a repair strategy was identified while listening to the recordings, a tick was put next to the strategy in question. Subsequently, the total number of repair strategies was calculated and the frequency of occurrence of each repair strategy was counted and turned into percentages. As far as the second research question is concerned, content analysis of the recording took place: Each repair strategy was put under scrutiny to come up with the functions behind its use.

\section{RESULTS AND DISCUSSION}

\subsection{The Repair strategies used by Algerian bilingual students:}

The adoption of the aforementioned research methodology reveals the existence of a variety of self-initiated repair strategies employed by Algerian bilingual students in response to communication breakdowns. In fact, a total of 109 repair strategies were inferred from the analysis of the casual conversations under investigation. These are categorized under nine main headings, namely: expansion, repetition, meta-repair, hesitation, abort and abandon, code switching, abort and restart, avoidance and questioning. Bearing on this point, it is noteworthy that the self-initiated repair strategies of deletion, replacement and insertion were not used by Algerian bilingual students. Similarly, three new self-initiated repair strategies came to the fore and were labelled by the researcher, namely, code switching, avoidance and questioning. In this respect, it may be noticeable that Algerian bilingual students made use of seven self-initiated self-repair strategies and two other-initiated self-repair strategies. The self-initiated selfrepair strategies include: expansion, repetition, meta-repair, hesitation, abort and abandon, abort and restart, and avoidance. However, the other-initiated self-repair strategies consist of code switching and questioning. Accordingly, the frequency of occurrence of each strategy was computed and turned into percentages as clearly displayed in the following table. It is worth mentioning that these are ordered from the most to the least used repair strategy.

Table: Frequencies and percentages of the set of repair strategies used by Algerian bilingual students.

\begin{tabular}{|c|c|c|}
\hline Repair strategies & Frequency & Percentage \\
\hline Expansion & 30 & $27,52 \%$ \\
\hline Repetition & 22 & $20,18 \%$ \\
\hline Meta-repair & 16 & $14,67 \%$ \\
\hline Hesitation & 12 & $11,00 \%$ \\
\hline Abort and abandon & 9 & $8,25 \%$ \\
\hline Code-switching & 7 & $6,42 \%$ \\
\hline Abort and restart & 7 & $6,42 \%$ \\
\hline Avoidance & 4 & $3,66 \%$ \\
\hline Questioning & 2 & $1,83 \%$ \\
\hline Total & $\mathbf{1 0 9}$ & $\mathbf{1 0 0}$ \\
\hline
\end{tabular}

\subsection{The functions of repair strategies used by Algerian bilingual students:}

This section is intended to shed light on the uses of each repair strategy and the aim behind its use. Accordingly, each repair strategy is analyzed independently 
accompanied with a set of examples taken from the investigated conversations. English translation of the extracts will similarly be presented. Instances of each repair strategy in question are written in bold. In addition, $\mathrm{A}$ and $\mathrm{B}$ refer to the interlocutors taking part in the conversation.

\subsubsection{Expansion:}

As clearly demonstrated in table 1, expansion is the most frequently used strategy for repairing communication breakdowns $(27,77 \%)$. This may be better characterized from the following extracts:

\section{Extract1:}

A: Sejbatek maYquuda?

B: wah, besaち Ђna maa ndiruhaas hakdaa.

A: batata waђadha?

B: batataw froma 3 w la faplǘr w naqluuha.

A: aah ok

\section{English translation:}

A: Did you like Makouda (Algerian dish)?

B: Yes, but we do not prepare it this way

A: Only potatoes?

B: Potatoes and cheese which are then fried.

A: Ah ok.

\section{Extract 2:}

A: baStuu l amn taS l-ZaamiSa xaater raちuu qalulhum belli l-filestinijiin rajђiin jdiru fayab mSa lxajmet loxriin.

B: aah kifeh fayab?

A: jek qotlek belGulhum zawija taShum xaater daru tsawar l-qaada taShum, qalulhum naђuhum maaђabuuf jnaђuhum aja yalquha, awal mara tesra $f$ masrad $l$ Zalijet!

\section{English translation:}

A: The University sent the police because they were told that Palestinians will make some trouble and fight with the other communities.

B: How will they make trouble?

A: I already told you that they closed the Palestinian corner during the event because they showed pictures of some Palestinian leaders, they asked them to remove them but they did not accept. So, they closed their corner, it happens in the communities' festival for the first time.

A glance at the aforementioned extracts reveals that expansion was indeed widely used by Algerian bilinguals as a means of communication repair. The aim behind the adoption of such repair strategy seems to lie in the fact that Algerian bilingual students intended to ensure that the addressee fully understand the intended message. As a result, more elaboration and illustrative examples are provided from the speakers like in the first example where the core of the participants' conversation revolves around the preparation of a traditional dish where B gives the list of ingredients following A's question: potatoes? Such results seem to be in line with Al Harahshah's (2015) interpretation.

\subsubsection{Repetition:}

The second frequently used repair strategy is repetition $(20,18 \%)$. This is most often used following a speaker's request for clarification. The following examples furnish crucial data bearing on this point:

\section{Extract 1:}

A: tsema 3ew gaS l-Zinsijet, gaS lii nasjonalitii?

B: Zew Zew,...,...,.., Zew kibeląna zawija Zew jsaqsu Sleh. Qolnelhum rana mSa filestin.

\section{English translation:}

A: It means that all nationalities were present?

B: They came, they came,...,...,.., they came when we closed our corner; they came and asked why we did so. We told them that we are supporting Palestine.

\section{Extract2:}

A: besaち normalmon yumiin jekfuni be nxamel?

B: mefi jumiin, saSa tekfik txamli qafek

A: $s a \hbar$ ?

B: tem tem. we jesђaq? Tem tem maa tesђaq waluu. நna lYam li fet ki kuna Ђabtin ruђna friina valizaa ana u amiira u Ziina xamalna நwajeZna.

\section{English translation:}

A: Do you think two days are enough for me to pack my luggage for travel?

B: Not two days, one hour is enough for you to pack your luggage.

\section{A: Really?}

B: Quickly, what does it need? Quickly, it doesn't need time. Last year when we were going to Algeria, we bought a suitcase, with Amira, and we came back and pack our luggage.

As displayed above, usually repetition is followed by elaboration which reinforces the repeated segment. Upon trying to disclose the aim behind the adoption of such strategy, it seems tempting to concede that repetition is 
aimed at emphasizing the point that speakers want to convey. Only by doing so, they become able to make sure that the addressee has understood the intended message adequately; that is, as the speaker wishes his message to be understood when undertaking the conversation. However, it is worth mentioning at this level of detail that repetition may be intentional or unintentional depending on the speakers' objective (Al Harahshah, 2015).

\subsubsection{Meta-repair:}

Meta-repair strategies may be defined as the inclusion of expressions which are meant to help clarifying the intended meaning. In English, such expressions may include "what I meant to say is that". The analysis of Algerian bilingual students' speech reveals an important and frequent employment of this strategy $(14,67 \%)$. The following extracts encompass vivid examples of the use of such expressions:

\section{Extract1:}

A: kife ken rad l-3aalijet lowriin? ana smeSt dzajer relqet!

B: Imuhim Juufi, dzajer yelqu u suurja,..,...,ih dzajer $u$ suurja haduu li fafthuum. Ana kunt dajra kuursi u qaSda.

\section{English translation:}

A: How was the reaction of other communities?

B: See, the most important thing is that Algeria and Syria closed their corners......yes, Algeria and Syria closed. I was there sitting on a chair.

As may be seen, expressions such as: "raak fajef ", "Imuhim fuuf ", "tsema”, “ちabit nqolek", "fhemti yek" (the translation of which is: you know, see the most important thing is that, it means that, I want to tell you, you got my point right respectively) appear to serve the purpose of assessing and checking the addressees' understanding of what the speaker is currently saying. Such evaluation appears to constitute a guideline aimed at helping the speaker modify and adjust his speech in such a way that fits the addressee's actual comprehension.

\subsubsection{Hesitation:}

Lying at the heart of hesitation, the use of pauses and silence when speaking was significantly noticed in Algerian bilingual students' adoption of repair strategies $(11 \%)$. Such occurrence of hesitation is better characterized in the extracts below (the dots represent silence. Each second is represented by three dots):

\section{Extract 1:}

A: Kife אanet la 3urnii tąek?
B: hajla wallah hajla.

A: lukan nqolek wasfiihali f kelma, kife J tawasfiha?

B: ,tawrija, நasit roђi tawrija.

\section{English translation:}

A: How was your day?

B: Great, it was great.

A: If I ask you to describe it in one word, how would you describe it?

B:,...,...,...,...,...,..., a warrior, I felt that I was a warrior.

\section{Extract 2:}

A:siiri waלdoxra kunt tetfara\} fiiha...taaא.........qotli espanjol.

B: aah,...,...,..,...,...,..,..., casa dii papel.

\section{English translation:}

A: You were watching another series,..., that of $, \ldots, \ldots, \ldots$, you told me it was Spanish.

B: Ah, .., .., .., .., ..,...,.., Casa de Papel.

A glance at the abovementioned extracts reveals the fact that hesitation may serve two main purposes: First, it provides the speaker with more time to organize his/her thoughts. In a similar vein, According to Levelt (1983) (cited in Al Harahshah, 2015), hesitation helps the speaker in checking the order, coherence and cohesion of his/her speech. Second, hesitation is considered as an indication that the speaker still holds the turn. Such observation seems to be in accordance with Ah Harahshah's (2015) findings. By doing so, communication breakdowns resulting from errors in turn taking and turn allocation are avoided.

\subsubsection{Abort and abandon:}

It was common when surveying the conversations under scrutiny to come across instances of such repair strategy $(8,25 \%)$ such as those found in the following extracts:

\section{Extract 1:}

A: Souf l-Sibada mahma ken tasb yziid $l$ aßer tahha,...,..,nfallah nrohuu nђwsu tema $f$ mekka wel madiina,...,...,..,..,kayen plajes faabin,...,..,d3abel uhud, ..., ..., .., ..., ..., ..., .., ...,.., maa naGraf was daret fiiha riijal!

B: rahuum 2-1.

\section{English translation:}

A: You know, the more you get tired in prayers, the better you are rewarded...... If God wills, we will visit Mekka and El Madina,...,...,...,..,There are beautiful places 
there,...,...,Uhud mountain

\section{wonder what Real Madrid did!}

B: The score is 2-1.

\section{Extract 2:}

A:wallah Sandhum raqs raaqi, besah maa fhamts ida hadiik la dons tradisjonel wela l-andunisijiin gaS hakda jefathuu, Sandhum wahed l-harakeet kifyul 3ded, ..., ..., ..., ..., ...,...ma byaw jefethu jkonektiw m Gaja.

B: Jkuun?

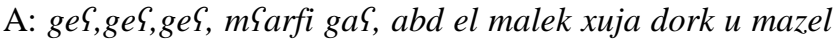
maafteђf.

\section{English translation:}

A: I swear, their dance is so refined, but I wonder if this is their traditional dance or do all Indonesians dance this way, their moves are somehow new and different $, . . ., \ldots, \ldots, \ldots, \ldots, \ldots$ They do not want to chat with me.

\section{B: Who?}

A: Everyone, everyone, everyone, all my acquaintances, my brother Abd El Malek has not opened his chat account till now.

Upon trying to throw light on the objective behind the use of abortion and abandon when embarking in a conversation, it seems tempting to assume that speakers usually adopt such technique when recognizing that they are saying something redundant or unimportant that doesn't attract the listener's attention. As a result, they shift to another topic that has nothing to do with the previous one (Al Harahshah, 2015). By doing so, the speaker acquires confidence regarding the attentiveness and enthusiasm that the addressee attributes to his/her speech.

\subsubsection{Code switching:}

The yielded findings indicate that Algerian bilingual students made use of code switching as a self-initiated repair strategy. Under our belts are some examples of the employment of code switching:

\section{Extract 1:}

A: jadraa tjabhum $f$ ramdan amel, qalek lar küliner taShum meji kima taSna.

B: hudaa tjabhum fhamtha besaち lar küliner hadi maa fhemthes.

A: non amel teSarfiha fen tabx taShum mefi kima taSna.

B: Aah saha huma tjebhum aylabijtu ruuz.

\section{English translation:}

A: I wonder if Jordanians cook the same dishes as ours. I heard that their art of cooking (l'art culinaire) is different.
B: Houda, I did understand what you mean by cooking, but what does l'art culinaire mean? I didn't understand it.

A: No Amel, you know it. It is fen tabx. We do not have the same kinds of dishes.

B: Ah ok. Almost all their dishes are made up of rice.

\section{Extract 2:}

A: framdan fkun jdirelkum lii kurs amel?

B: euh,...,...,..,lii kurs? teSarfini fel fransi huda. wef maSnetha?

\section{A: Ђabit nquul fkun jeqdii f ramdan \\ B: aah lqodien dajmen Sla ba}

\section{English translation:}

A: Who goes to the market to buy what you need (les courses) during Ramadan?

B: Euh, ...,...,...,les courses? You know my level in French Houda. What does it mean?

A: I want to say who goes to the market (Jkun jaqdii) in Ramadan

$\mathrm{B}:$ Ah, it is always my father who goes there.

As the above extracts evince, code switching is used when a communication breakdown results because of language choice. As it was previously held in the present paper, Algerian bilinguals differ at the level of proficiency they have in the second language; that is, French. On these grounds, two categories of Algerian bilinguals may be identified: while some are considered as simultaneous bilinguals and as a result they are equally proficient in both languages, others are consecutive bilinguals and consequently more proficient in their mother tongue. In this respect, when interaction takes place between these two types of bilinguals, some communication breakdowns might come to the fore. One way of approaching the problem is the use of code switching. In the first extract, speaker A switches from French "l'art culinaire" to Standard Arabic "فن الطبخ". On these grounds, when the speaker utters an expression in French that the addressee does not understand, the latter asks for clarification and the speaker switches to either Algerian Arabic (as in extract 2) or to Standard Arabic (like in the first extract) to make sure that the message is appropriately and adequately transmitted to the listener

\subsubsection{Abort and restart:}

The following examples are a concrete characterization of such strategy:

\section{Extract 1:}


A: besaち l-ordon en gron pe ji maakuntf Ђasbuu

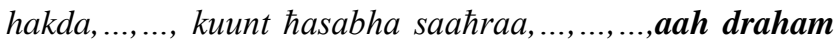

\section{bezaaf, draham maarane qadriin nGifuu.}

B: saち, Sandek l-ђaq bezaaf.

\section{English translation:}

A: But Jordan is a great country, I didn't expect to find it like that, ...,..., I thought it was a deserted place, ...,.., .., ah money, it is too much, we can barely survive.

B: Yes, you are right.

Speakers adopting this repair strategy abort or stop their speech for a while and then restart talking about the same point from another perspective (Ah Harahshah, 2015). By way of illustration, in the first extract, speaker A was talking about the beauty of Jordan, he then cuts off his speech for a while. When he restarts, he starts talking about economic life in Jordan. This self-interruption technique appears to take place when the speaker suspects that he/she may have said something inappropriate or divergent from the main topic. The speaker thus moves from a prospective to a retrospective process. Once he has reviewed his previous, just uttered speech, he/she then restarts a new turn within the same topic but from a different angle unlike the previously mentioned repair strategy of repair and abandon in which a complete shift of topic does occur following the speakers' interruption of the ongoing talk. This analysis appears to be in parallel with Al Harahshah's (2015) interpretation of the dynamics of this self-initiated repair strategy.

\subsubsection{Avoidance:}

Avoidance is another strategy employed by Algerian bilingual students when they wish to indicate their uncertainty regarding some fact as exhibited in the following passages:

\section{Extract 1:}

A: had l-film taani Jbeb,...,dajerkima lii film taS indjana Zons,...,...,kajen wahed jroh $l$ madiina qdiima $3 a j a ~ f$ suurja...maaneGraf wesamha, ..,euh, .., ...,...,..,...iirem, iiremðet el Simed.

B:aahsaちa.

\section{English translation:}

A:This movie is also great, it resembles Indiana john's movies, ...,...,There is one who goes to an ancient city in Syria, ...,I don't know its name, ...,euh, ..., .., ..., ..., ..,Irem, Iremðet el Imad.

B: Ahok.

\section{Extract 2:}

A: aちkili wef derti ljuum,...,smeSt beli sraw aSmel fayab wela kife, ..., ma fhemts?

B: maa Slabaliif. Huиma jqulu waђed zuи了 bnet semৎu hadra $f$ zawija l-filestinija $u$ raђuu neqluha $l$ idaret $l$ ZaamiSa beStu l emn taS l-ZaamiSa.

\section{English translation:}

A: Tell me what you have done today, ..., I heard that there were some conflicts, or what, ...,..., I didn't understand.

B: I don't know. It is said that two girls heard in the Palestinian corner and they went to the University administration. As a result, the university sent the police as they were told that Palestinians will fight with the other corners.

In essence, the use of such technique is held to be grounded on the speaker's desire to display his uncertainty with regard to a given fact. Indeed, expressions such as "wallah ma Slabali", "wallah ma rani Sarfa", "ma rani SGaraf" are used by the speaker following the addressee's request for clarification to give a pointer to the addressee that he/she is not sure about the validity, accuracy and legitimacy of his following talk.

\subsubsection{Responding by questions:}

A surprising result yielded through the analysis of the provided conversations indicates the use of questions as a repair strategy. In fact, in some cases when the addressee asks for clarification, the speaker responds by using a question. Such strategy may be categorized under the repair strategy of other-initiated self-repair (Hutchby and Wooffitt, 1998, Cited in Al Harahshah, 2015). Such occurrences are demonstrated in the extracts below:

\section{Extract1:}

A:Sefti ki kuna xarZin qaletana hadik l-ordonija rakum rajhiin tetfarZu maa Sandkumffdzajer hakda, wasamha?

B: wasamha fatma.

A: mem hadik wasamha?,..,nsitha, .., .., maha?

B: mefi maha, ..., yada?

A: yada, yada,..., qatelha f dzajer Sandhum Jta w maSrufiin biha.

\section{English Translation:}

A: You remember when we were leaving, that Jordanian woman asked us if we were going to see the rain and whether it rains in Algeria. What is her name?

B: Her name is Fatma.

A: And what is the name of the other lady?,..., I forgot, ..., ...,Maha?

B: Not Maha, ..., Ghada? 


\section{B: Ghada, Ghada,..., she told her that even in Algeria it rains and that Algeria is known for that.}

\section{Extract 2:}

A: hadek Ze ana mazel maabdit fiih. lYebt yiir la partii lewla, ...,we wotli bayi taStini Ze loxer? ki jsemuh?

\section{B: Cause3}

A:aah ...wah cause3.

\section{English translation:}

A: I haven't started the other game, I only played the first part,..., What is the name of the other game you wanted to give me? What is its name?

B: Cause 3

A: Ah, ...,yes cause 3 .

It appears that the speaker's aim behind the use of questions like: "wasamhahadik", "kiysamouhansitha?" (what is her name? )is his/her desire to get some help from the listener to complete his/her current utterance. This usually happens when the speaker is looking for a word that he/she cannot remember.

\section{LIMITATIONS OF THE STUDY}

In spite of the stepwise development followed to conduct the present study, a number of limitations were inevitable.

To start with, a representativeness issue is worth pointing out. In fact, as the field work started at the end of the second semester, all students were busy preparing for the exams. Such inappropriate circumstances resulted in the limited number of the participants. Consequently, the results obtained may not be representative of the whole population. If the number of participants was higher, richer data would have consolidated the research findings.

Second, as far as the period of data collection is concerned, one week is not enough to sufficiently and adequately collect data. Perhaps, if more recordings took place, results would have been richer and diversified.

Last but not least, having recorded the participants only for ten minutes represents a weighty problem as it minimizes the amount and types of repair strategies that Algerian bilingual students made use of when facing communication breakdowns. If conversations lasted for more time, the results would have been richer and perhaps more repair strategies may have come to the fore; ones that were not mentioned before by the researcher.

\section{FURTHER RESEARCH}

Due to the undertaking conditions of the present study and the data obtained, need is felt for supporting the present study findings by carrying out further research with a larger number of participants. Such supplementary inquiry would approve the degree to which the yielded data are acceptable and representative. Additionally, future investigations can utilize a variety of instruments, such as video-recordings to investigate the non-linguistic aspects of repair strategies. The inclusion of such tool can undoubtedly consolidate the results to be obtained. For an extended knowledge with regard to the set of repair strategies used by Algerian bilinguals, forthcoming studies might explore the difference between monolingual and bilingual's use of repair strategies. Similarly, future research might shed light on the way simultaneous and consecutive Algerian bilinguals make use of repair strategies based on their linguistic experience. The findings of comparable studies appear to provide teachers, students, and stakeholders alike with a wealth of information regarding the best initiatives of using effective and efficient repair strategies whenever needed during communication.

\section{CONCLUSION}

In the last couple of decades, ample attention was pointed towards the occurrences of communication breakdowns and the set of repair strategies aimed at solving such a complication. Accordingly, the present paper was intended to delve into the intricacies of the set of repair strategies adopted by Algerian bilingual students. The yielded findings demonstrate that Algerian bilingual students' repair strategies fall under nine general headings; namely: expansion, repetition, meta-repair, hesitation, abort and abandon, code switching, abort and restart, avoidance and questioning. However, it is worth mentioning at this level of detail that such repair strategies serve different purposes depending on the type of communication breakdown taking place on the one hand and on the aim of the speaker on the other hand. In a similar vein, it must be borne in mind that further research will undoubtedly constitute a fruitful path of inquiry as it is hoped to lend further support and enrichment to the present study.

\section{REFERENCES}

[1] Al Harahsheh, A. M. (2015). A Conversation analysis of self-initiated repair structures in Jordanian spoken Arabic. Discourse Studies, 10:1-18. 
[2] Antos, G. (2011). Handbook of Interpersonal Communication. The Hague, the Netherlands: Mouton De Gruyter.

[3] Comeau, L.,Genesee, F., and Mendelson, M. (2010). A comparison of bilingual and monolingual children's conversational repairs. International Journal of Bilingualism, 3: 3-4.

[4] Eisenberg, E. M. (2010). Organizational Communication: Balancing Creativity and Constraint. New York, NY: Saint Martin's.

[5] Gafaranga, J. (2012). Language alternation and conversational repair in bilingual conversation. International journal of bilingualism, 16 (4): 501-527.

[6] Heritage, J. (1984). A Change-of-State Token and Aspects of its Sequential Placement. In: Atkinson, J.M and Heritage, John (eds.). Structures of social action: Studies in Conversation Analysis, pp. 229-345.

[7] Hutchby, I., and Wooffitt, R. (1998). Conversation Analysis: Principles, Practices and Applications. Cambridge: Polity Press.

[8] Keyton, J. (2011). Communication and Organizational Culture: A Key to Understanding Work Experience. Thousand Oaks, CA: Sage.

[9] Levelt, W. J. (1983). Monitoring and self-repair in speech. Cognition, 14: 41-104.

[10] Lunenburg, F. C. (2010). Communication: The process, barriers, and improving effectiveness. Schooling (1): 1-11.

[11] Markee, N. (2000). Conversation Analysis. Lawrence Erlbaum, Mahwah: NJ.

[12] Rabab'ah, G. (2013). Strategies of repair in EFL learner's oral discourse. English Language Teaching, 6 (6): 123-131.

[13] Sacks, H.,Schegloff, A. E., and Jefferson, G. (1974). A simplest systematics for the organization of turn-taking for conversation. Language, 50 (4): 696-735.

[14] Schegloff, E. A. (1979). The Relevance of Repair to Syntaxfor-Conversation. In: Givon T (ed.). Syntax and Semantics: Discourse and Syntax. New York: Academic Press, pp. 261286.

[15] Sparks, R. B. (1994). The Structure of Self-Repair in English Conversation. PhD Dissertation, University of Colorado at Boulder, Boulder, CO.

[16] Steensig, J. (2003).Conversation analysis and the study of bilingual interaction. Working Papers on Language and Linguistics, 31(5): 796-818.

[17] Tarone, E. (1977). Conscious Communication Strategies in Interlanguage: a progress report in $\mathrm{H}$. Brown, C. Yorio, and R. Crymes (eds). On TESOL '77.Washington D.C.: TESOL.

[18] Wooffitt, R. (2005). Conversation Analysis and Discourse Analysis. London: Sage Publication Ltd. 